\title{
Ageing-friendly communities and social inclusion in the United States of America
}

\author{
ANDREW E. SCHARLACH* and AMANDA J. LEHNING $\dagger$
}

\begin{abstract}
Synthesising the social capital and ageing-friendly communities literature, this paper describes how efforts to make communities more ageing-friendly can promote social inclusion among older adults. Making existing communities more ageing-friendly involves physical and social infrastructure changes that enable older adults to pursue lifelong activities, meet their basic needs, maintain significant relationships, participate in the community in personally and socially meaningful ways, and develop new interests and sources of fulfilment. Such efforts can enhance bonding, bridging and linking capital, and thereby promote social inclusion. The authors discuss the link between ageing-friendly communities and social inclusion, and provide examples of programmes with potential to change existing communities into ones that promote the social inclusion of older adults.
\end{abstract}

KEY WORDS-ageing-friendly communities, social inclusion, housing, older people, community, United States.

\section{Introduction}

In the United States of America (USA), the past decade has witnessed a rapid growth in the number of local, state, national and international initiatives aimed at helping communities to become more ageing-friendly. Making existing communities more ageing-friendly involves modifying social and physical environments so that elderly residents can meet age-related needs while continuing to live in their familiar homes and communities for as long as they choose. Examples of ageing-friendly environmental modifications include opportunities for social integration and meaningful activities; landuse designs that increase social contact and reduce automobile dependence; affordable and accessible housing that allow older adults to remain in familiar neighbourhoods; and a wide range of transportation and mobility options. In this article, we explore how ageing-friendly communities can

* School of Social Welfare, University of California, Berkeley, California, USA.

$\dagger$ School of Social Work, University of Michigan, Ann Arbor, Michigan, USA. 
promote the social inclusion of older residents, with a particular focus on the US context. We begin by providing an overview of the emerging concept of ageing-friendly communities. We then discuss social inclusion and the factors that contribute to increased risk for social exclusion among older adults, including economic vulnerability, environmental barriers and ageist societal norms. This is followed by an exploration of the environmental context of social inclusion, including the link between ageing-friendliness and social inclusion, the ways in which social and physical environments can enhance social inclusion of older community members, and an analysis of select examples of ageing-friendly initiatives in the USA and their potential implications for social inclusion. We conclude with a discussion of policy implications for the USA and other countries and suggestions for future research.

\section{The importance of ageing-friendly communities to social inclusion}

Communities can be considered 'ageing-friendly' to the extent that they enable elderly community members to reside in familiar residences for as long as they wish (i.e. age in place), while having opportunities to meet agerelated needs through participation in community life. Ageing-friendly communities are characterised by physical and social environments that promote social inclusion of older community members by providing opportunities and supports in five areas that have been found to be of particular relevance in the latter part of the lifecourse: (a) continuity (i.e. absence of barriers to continued participation in long-standing activities and interests); (b) compensation (i.e. the ability to meet basic health and social needs in spite of age-related disabilities); (c) connection (i.e. opportunities to develop and maintain meaningful interpersonal relationships); (d) contribution (i.e. opportunities to participate in and have an impact upon one's social environment; and (e) challenge (i.e. development of stimulating new activities and interests) (Lehning, Chun and Scharlach 2007; Scharlach 2009).

Ageing in place has emerged as an important focus of public interest and public policy in the USA. A national survey by AARP (2000), for example, found that 82 per cent of elderly Americans want to continue to live in their current homes for the rest of their lives even if they need help caring for themselves, reflecting societal values of independence, privacy and personal control. Recent directions in US ageing policy likewise have focused on 'rebalancing' public expenditures so as to prevent or delay institutionalisation and promote ageing in place, in part as a means of reducing government fiscal liability (Scharlach and Lehning 2011). The 2010 
Patient Protection and Affordable Care Act (PPACA), for example, includes a 'Balancing Incentive Payment Program', which provides fiscal incentives for states to spend less on institutional care and more on home and community care, and extends authorisation of the 'Money Follows the Person' demonstration project, which provides US $\$ 1.75$ billion in federal funding to assist poor disabled individuals to move from institutional to community settings (National Senior Citizens Law Center 2010). However, despite the increased attention to ageing in place, non-institutional services are highly fragmented and poorly co-ordinated and receive only about 30 per cent of federal expenditures on long-term services and supports, while communitybased social and nutrition programmes receive less than 1 per cent of all such expenditures (AARP Public Policy Institute 2008).

US public policy has given little attention to the community contexts within which elders reside, despite the potentially salient influence of neighbourhood physical and social contexts on older adults' ability to age in place. Moreover, a focus on ageing in place that does not simultaneously consider the social environment and its importance in elders' lives runs the risk of fostering social isolation and exacerbating social exclusion (Levitas et al. 2007). Thomas and Blanchard (2009), among others, have advocated that 'ageing-in-place' be replaced by 'ageing-in-community' as a policy goal, reflecting a belief that independence and self-reliance are insufficient if not accompanied by opportunities to maintain important interpersonal bonds and participate in meaningful social roles. Neighbourhood contexts may be especially important to today's elders (Phillipson et al. 1999), who not only spend more time in their homes and neighbourhoods compared to younger age groups (Forrest and Kearns 2001), but have spent more time in their homes and neighbourhoods over the course of their lives compared to previous generations (Phillipson et al. 1999).

In the absence of a comprehensive national policy, a number of private organisations and local governments in the USA have developed initiatives in recent years to help communities become more ageing-friendly. These include the Robert Wood Johnson Foundation's Community Partnerships for Older Adults (www.partnershipsforolderadults.org), the Visiting Nurse Service of New York's AdvantAge Initiative (www.vnsny.org/advantage), and the National Association of Area Agencies on Ageing and Partners for Livable Communities' Ageing in Place Initiative (www.ageinginplaceinitiative.org), among others. In addition, two US cities (New York City and Portland, Oregon) are participants in the World Health Organization's (WHO) Global Age-friendly Cities programme (www.who.int/ageing/ age_friendly_cities/en/index.html). These initiatives use a variety of terms, including 'livable', 'elder friendly', and 'communities for all ages', but they share the common goal of modifying the physical and social 
environment to improve the health and wellbeing of older residents and increase elders' social inclusion.

\section{Social inclusion}

Social inclusion has been described primarily as a response to structural barriers that deny individuals and groups the ability to participate fully in the benefits of society, with particular attention to access to resources, such as goods, services, power and control (Cass, Shove and Urry 2005; Marsh and Mullins 1998). Moreover, social inclusion is a relational concept that reflects the quality and quantity of social ties (Silver and Miller 2003). Social inclusion, as used in this article, refers to three central characteristics at the interface of individuals and their environments: (a) social integration; (b) social support; and (c) access to resources. Social integration reflects the extent to which individuals are embedded within a network of meaningful social bonds and societal structures, as evidenced by the size, density and intensity of social relationships and contacts (House, Umberson and Landis 1988). Social support refers to the extent to which those social bonds enable network members to obtain help when they need it (Berkman 200o). House (1981), for example, identified four main types of social support: emotional, appraisal, informational and instrumental. Resource access reflects Townsend's notion that social relationships serve a potential instrumental function in promoting the wellbeing and fulfilment of network members (Townsend 1979).

Social inclusion may have a variety of potential benefits for older persons, such as the following: reciprocal social exchanges that foster interdependence rather than inequity and disempowerment; social integration that supports social identification; role fulfilment and preservation of selfconstruct and self-esteem; social recognition from community members and one's self; meaningful social interaction; and social agency rooted in mastery, self-efficacy, and perceived control of oneself and one's environment.

Social exclusion of older persons in the USA in part can be understood in terms of economic vulnerability. While some older adults are quite well-off, in some states nearly one-half of elderly persons have incomes below what is necessary for basic economic security (Center for Community Economic Development 2009). This is especially true for women and racial and ethnic minorities (due to lifelong processes of cumulative disadvantage); thus, onethird of elderly African American women and nearly one-half of Latina women living alone have incomes below the federal poverty rate (US Department of Health and Human Services 2010). Moreover, 77 per cent of 
elderly persons in the USA are dependent upon Social Security, the public pension system, for all or some of their incomes (National Council on Ageing n.d.).

For older persons, social exclusion not only reflects economic disadvantage, but also disabling environments and ageist societal norms and values (Jette 2009). Increased vulnerability to potentially disabling physical and cognitive conditions, coupled with the inadequacies of the physical and social environment, can limit full societal participation of older persons. In a world designed for younger persons, even normal processes of ageing may make it difficult or impossible for older persons to engage fully in meaningful social activities and roles (Schonfelder and Axhausen 2003). Environments that are ill-designed for normal ageing-related changes therefore may create access barriers that contribute to reduced elder social participation and intergenerational solidarity, potentially resulting in decreased status, decreased participation in decision-making processes and decreased control over one's own life (Silver and Miller 2003).

Social exclusion among older persons results not only from decreased access to valued roles and opportunities, but also from the ageist norms that define those roles as valuable. In the USA, norms regarding what is desirable, worth doing and worth having reflect the values and priorities of young and middle-aged adults (e.g. employment), rather than those in a later stage of the lifecourse (Scharf et al. 2001). The concept of social exclusion itself has been defined by characteristics more relevant to working-age individuals, such as 'exclusion from the resources of a dignified life: an active labor market, good quality health care and consumption opportunities, and, finally, integration in the wider networks of civic life' (Schonfelder and Axhausen 2003: 273). Social exclusion typically is conceptualised as the inability to 'participate in the normal activities of citizens in that society' (Burchardt, Le Grand and Piachaud 1999: 229), echoing Townsend's original relational conception of poverty as the level below which individuals can no longer participate in the normal life of the society to which they belong (Townsend 1979; see Warburton, Ng and Shardlow 2012, this issue). In this way, the concept of normal life may ignore the realities of older adults and other marginalised groups (Levitas 1996).

In considering social inclusion of older persons, we suggest a more developmental perspective that conceptualises social inclusion not only as participation in activities that have been valued at earlier points in one's life, but also those that are valuable and relevant toward the end of one's life. These include a range of social and communal contributions outside the paid labour force, such as care-giving, that involve both giving and receiving care, intergenerational solidarity, and appropriate levels of physical, mental and social stimulation. 


\section{The environmental context of social inclusion}

Social inclusion can be understood not simply as a characteristic of individuals, but of the communities within which those individuals live. Physical and social contexts themselves can be 'inclusive' or not-either facilitating or serving as barriers to resource access, social integration and social support. Many neighbourhoods in the USA at the beginning of the 21 st century are characterised by physical and social environments that exclude older adults from social and community life. For example, more than two-thirds of older adults in the USA live in suburban and rural communities (Frey 2007), which can present physical barriers to social inclusion, particularly for older adults with a disability. Suburban communities in the USA are often characterised by low-walkability neighbourhoods dominated by single-family homes, long block lengths, and the absence of stores and services easily accessible by foot (Saelens et al. 2003). As another example, social exclusion especially is an issue for older adults with low incomes and assets, who are more likely to be ageing in place in neighbourhoods characterised by either a rapid turnover of people and services (i.e. zones of transition) or out-migration of services (i.e. termed 'institutional isolation' by Gans 1972; Scharf, Phillipson and Smith 2005). In this regard, Phillipson (2007) posits that today's elderly can be divided into two groups: those who can choose to change their physical and social environment by moving to a new community, and those who must remain in communities often characterised by changing or unsupportive physical and social environments.

Emerging conceptual developments and programmatic innovations suggest a number of possibilities for modifying social and physical environments in order to make existing communities more ageing-friendly and promote the social inclusion of older residents.

\section{Social environment}

The concept of social capital provides a useful framework for understanding the potential ways in which social environments can foster social inclusion. Pierre Bourdieu's original definition of social capital referred to 'the aggregate of the actual or potential resources which are linked to possession of a durable network of more or less institutionalised relationships of mutual acquaintance or recognition' (Bourdieu 1986: 248). As Portes notes, Bourdieu's concept of social capital reflects both (a) the existence of established social relationships and (b) the amount and quality of resources made available through those relationships (Portes 1998). Putnam (1995) 
and others broadened the original concept of social capital to refer to community or organisational characteristics that foster mutually beneficial social interaction among community members.

Simply put, social capital can be understood as 'social networks and norms of reciprocity' and the benefits derived therefrom (Putnam 2004: 668). Three types of social capital are postulated: bonding, bridging and linking (Szreter and Woolcock 2004). High levels of social capital are apt to be especially important for older adults, who may be more dependent upon community social networks than are other age groups, in part because of physical and social barriers that limit options for movement and interaction across community boundaries, and in part because of the developmentally relevant salience of existing interpersonal connections towards the end of life (Carstensen 1995). However, the existence of high levels of community social capital may be somewhat less relevant for community members with relatively high personal capital (e.g. health and wealth). Some highly resourced individuals, for example, may prefer the freedom and individual choice available in communities without firmly established norms and tight social networks. Moreover, those with high personal capital are better able to migrate from their current communities to those with better amenities, including good weather and ample leisure opportunities (Conway and Houtenville 2003).

Community social capital, while especially important for older adults with fewer physical, social or economic resources, may itself be less extensive in the relatively under-resourced neighbourhoods within which economically vulnerable individuals are apt to reside. Moreover, the concept of social capital has been criticised as focusing on adaptation to political contexts that allocate resources inequitably rather than striving to alter the unjust distribution of power and privilege (Navarro 2002). In this regard, it is notable that there is some evidence of greater social capital in societies with relatively strong welfare states, as opposed to countries such as the USA with relatively weak and disparate public support systems (Therborn 1995). Social capital also has been criticised for its utilitarian bias, portraying human relationships primarily in terms of their instrumental or economic benefits rather than as having value and meaning in and of themselves (Navarro 2004).

Empirical research has demonstrated that high social capital and social integration, including participation in social activities and social networks, are associated with a number of salutary outcomes for older persons, including fewer symptoms of depression (Glass et al. 2006), less functional impairment (Miller and Weissert 2000), improved health (e.g. Kawachi, Kennedy and Glass 1999) and a reduced risk of mortality (Glass et al. 1999). For older adults with chronic illness or disability, social networks and social 
activity may be particularly important for life satisfaction (Jang et al. 2004). Emotionally supportive relationships with others are also associated with measures of good health, including reduced odds of nursing home placement (Giles et al. 2007) and delayed mortality (Lyyra and Heikkinen 20o6). Moreover, in his study of the 1995 Chicago heat wave, Klinenberg (2002) found that heat-related deaths among older adults were more likely to occur in those neighbourhoods with low levels of social interaction, and that even socially isolated elders were able to survive if their immediate social environment was characterised by strong social ties and frequent interactions between neighbours.

Neighbourhood-based social capital may be becoming less available to older persons, however. Although the evidence is somewhat mixed (Phillipson 2007), it appears that place-based social ties in many societies are gradually being replaced by more geographically dispersed associationalbased ties (Cass, Shove and Urry 2005; Forrest and Kearns 2001), which tend to be more highly valued by community members who are younger and/or employed (Guest and Wierzbicki 1999). Data from the General Social Survey, for example, indicate that in the USA between the 1970s and the 199os, the importance of neighbourhood-based social ties steadily declined while that of non-neighbourhood ties slightly increased (Guest and Wierzbicki 1999). Further longitudinal research is needed to ascertain whether declining neighbourhood social capital exacerbates social exclusion, or has other potential implications for the health and wellbeing of older adults and other vulnerable groups (Cannuscio, Block and Kawachi 2003).

Social environments that are more ageing-friendly may have the potential to increase social capital and foster enhanced social inclusion among elderly residents. To the extent that they remove barriers to social relationships within and across age groups, ageing-friendly communities may create opportunities for the enhancement of bonding and bridging capital, respectively, as well as increased access to resources outside one's own community, potentially reducing the amount and intensity of formal assistance required to respond to disabling conditions. Furthermore, social engagement, whether involving formal organisational participation or informal care-giving roles, provides a mechanism for older community members to contribute to the social capital of their communities through the generative transmission of life-long experience and wisdom (MorrowHowell, Hinterlong and Sherraden 2001).

Promoting social capital and social inclusion is an integral component of a number of initiatives in the USA that have the goal of helping communities to become more ageing-friendly. However, these initiatives, while promising, generally represent limited approaches that are not well-integrated with 
existing administrative and financing structures, evoking some concern regarding their comprehensiveness, effectiveness, and sustainability. The following examples, while not intended to be representative of all ageingfriendly community initiatives, highlight some of the current approaches in the USA designed to address social environmental barriers to social inclusion. These examples are selected, based on their comprehensiveness and potential contributions to social inclusion, from 293 community ageing initiatives in the USA identified through an internet search using prompts such as: 'ageing friendly', 'elder friendly' and 'ageing in place', as described elsewhere (Lehning, Scharlach and Wolf 2012).

A key feature of many ageing-friendly community initiatives involves asking older adults to serve as critical stakeholders in helping to set priorities, propose solutions for action and monitor progress (Lehning, Scharlach and Wolf 2012):

- The Portland Age-friendly Cities Project was designed to promote the social inclusion of elders by involving older city residents as key information sources regarding the age-friendliness of the city, reflecting a developmental approach designed to draw upon elders' unique perspectives and strengths. In Portland, Oregon, as in the other 33 cities participating in the WHO's Global Age-friendly Cities programme, older adults and other stakeholders participated in focus groups where they identified and assessed the adequacy of eight elements considered essential to an agefriendly city, including 'respect and social inclusion' and 'social participation' (WHO 2007). However, while WHO age-friendly cities initiatives such as the one in Portland offered elderly community members opportunities for potentially meaningful social roles which may contribute to enhanced resource development and access, such initiatives apparently gave less attention to social capital development designed to foster sustained social integration and social support. In 2010, WHO launched a Global Network of Age-friendly Cities (www.who.int/ ageing/age_friendly_cities_network/en/index.html), to support participating cities (now also including New York City as a second US participant) in implementing the recommendations identified by older adults and other stakeholders.

Some initiatives in the USA engage older residents not only as stakeholders providing valuable input, but also as key agents in promoting social capital formation and social inclusion:

- The Community Ambassadors Program (CAPS) in suburban Northern California (www.capseniors.org), for example, utilises elderly volunteers from seven historically under-served ethnic and faith-based communities 
(Indian, Taiwanese, Muslim, Latino, Sikh, Filipino, and multiethnic Christian) to serve as 'ambassadors' between older adults within these communities and the existing ageing services network. This project has generated both linking capital, as ambassadors inform community members about the availability of services, and inform service agencies about the particular needs and values of their communities; as well as bridging capital, as ambassadors meet with family groups and social networks to foster enhanced intergenerational understanding and support. Further, social integration is enhanced as ambassadors meet with groups of community seniors in their own language and culture where the seniors naturally congregate, thereby promoting bonding capital (Blair 2010; City of Fremont 2011). That development of the CAPS programme required more than one million dollars in private foundation funding prompts some concerns regarding its replicability in other communities.

- Similarly, the 'Village' model (www.vtvnetwork.org), based on the example of Beacon Hill Village in Boston (www.beaconhillvillage.org), promotes social inclusion through a combination of bonding, bridging, and linking capital. Villages are grassroots, consumer-driven membership organisations typically developed and governed by older community members that provide a variety of services and involvement opportunities in exchange for annual dues. This includes access to core Village services; the potential for linking capital through referrals and discounts to vetted outside services, such as home health care; opportunities to develop bonding social capital through member-planned social activities; and substantial opportunities for social engagement, particularly through volunteer and local leadership activities (Scharlach, Graham and Lehning 2012 ). However, to date, most Villages have been developed by relatively well-resourced individuals and communities (e.g. only those older adults with annual incomes of less than $\$ 40,000$, on average, are eligible for discount memberships), and Latinos and African Americans are underrepresented among current Village members (Scharlach, Graham and Lehning 2012). Moreover, concerns have been raised regarding the longterm sustainability and effectiveness of the Village model, as most Villages are operationally and financially independent from existing service delivery and financing systems (Scharlach, Graham and Lehning 2012).

There are also examples of ageing-friendly community initiatives in the USA that focus particularly on the development of bridging social capital by promoting meaningful social bonds among individuals of diverse ages and ethnicities. 
- The Monument Corridor Project (http://www.cceb.org/programs/monumentcorridor-senior-program.htm), for example, brought together elderly volunteers and community leaders to design a friendly visiting programme that matched socially isolated Latino elders with low-income mothers living in a low-income neighbourhood in Concord, California. The home-bound elderly benefited from intergenerational social support from neighbours, increased access to health and social resources outside their immediate cultural community, and opportunities to transmit culturally relevant wisdom to subsequent generations. At the same time, the friendly visitors gained a meaningful social role that fostered a greater sense of social integration and inclusion in their community (Scharlach and Sanchez 2011). However, financial and operational support for the project eventually declined substantially, partially as a result of professional and cultural differences regarding the appropriate roles of indigenous helpers and formal service delivery systems (Scharlach and Sanchez 2011).

- Communities for All Ages (CFAA; communitiesforallages.org) also fosters social inclusion through an intergenerational approach to local community-building that involves residents of all ages, local organisations, policy makers, funders, and media. Attempts to break through existing agespecific 'silos' and generational barriers include, for example, multigenerational neighbourhood learning centres and community life centres, and organised Farmers Markets and Arts Festivals to promote cross-cultural and cross-age understanding. However, the extent to which intergenerational programmes and structures such as these result in sustained social capital formation and social inclusion has not yet been assessed.

- Generations of Hope (www.generationsofhope.org) represents an intergenerational approach designed to promote social capital development and social inclusion, which creates intentional communities fostering mutually beneficial social relationships between older adults and younger residents who are experiencing personal and social challenges, such as substance abuse, domestic violence or homelessness (Eheart et al. 2009). In Hope Meadows, Illinois, for example, elders serve as tutors, mentors, companions and 'honorary grandparents' for children who have behavioural and emotional problems, with the goal of fostering 'family' connections which in turn will help support the seniors as they age. To date, the complete model has been implemented in only one location, and requires a substantial investment of human and economic resources. Moreover, the intended benefits for children, families and older community residents may take many years to materialise.

Initiatives such as these reflect emerging community-based strategies in the USA to promote social inclusion of older adults. To a large degree, these 
initiatives have been developed independently from the existing ageing network and its services delivery and financing system (Casas 2010). Reliance on private funding and lack of integration with existing service networks prompts questions regarding the long-term sustainability of initiatives such as these. None of them has been rigorously evaluated to date, making it impossible to know how effective they may be in promoting social inclusion or other personal or communal benefits. In addition, as noted above, simply having strong social networks within restricted programmes and communities does not guarantee that older adults will have access to valued resources, especially if the network members are under-resourced because of structural disadvantage or social exclusion. Ultimately, the extent of community social capital reflects structural and social features that serve to shape the nature and intensity of social interactions, the resulting social cohesion and 'sense of community' (McMillan and Chavis 1986), and the real and perceived ability of community members to access the resources necessary for full social inclusion.

\section{Physical environment}

Although the social exclusion literature has traditionally neglected aspects of the physical environment, in the past decade researchers have paid increased attention to the spatial dimension of exclusion (e.g. Cass, Shove and Urry 2005; Schonfelder and Axhausen 2003). The physical environment that an individual encounters in daily activities, his or her 'activity space' (Casas 2007; Schonfelder and Axhausen 2003), has been found to be an important indicator of social exclusion (Schonfelder and Axhausen 2003). Activity space is determined in large part by mobility options and the spatial distribution of supports and services (Schonfelder and Axhausen 2003). Individuals whose activity spaces are physically excluded tend to be socially excluded as well, affording reduced access to social as well as material resources (Schonfelder and Axhausen 2003).

Declines in physical functioning serve as primary barriers to mobility. Because many older adults no longer work and therefore may spend a great deal of time in their homes and neighbourhoods (Forrest and Kearns 2001), the physical infrastructure of the surrounding environment, including the walkability of streets and the supply of shops and services, may be particularly important. In addition, older adults who live in non-urban areas and can no longer safely operate their own vehicles are especially likely to experience difficulties in accessing resources and participating in community life outside the immediate neighbourhood because of limited transportation 
services (Rosenbloom and Herbel 2009). As described in more detail below, this is particularly important in the USA, where the majority of the population lives in suburban and exurban areas characterised by long distances between residential and commercial areas and limited public transportation.

The physical components of an ageing-friendly community include community designs that promote walkability, adequate forms of transportation, and a wide range of housing options (AARP Public Policy Institute 2005; Hanson and Emlet 2006; National Association of Area Agencies on Ageing $\left(\mathrm{N}_{4} \mathrm{~A}\right)$ and Partners for Livable Communities 2005).

\section{Community design}

The physical layout of the majority of existing communities in the USA contributes to the social exclusion of older adults (Schilling and Linton 2005), primarily as a result of community designs that limit the ability of individuals with functional impairments to engage in everyday activities (Clark and George 2005).

In recent years, public health researchers in the USA (e.g. Satariano 1997) have called for changes in community design to promote the mobility and independence of older residents. These changes include developing walkable neighbourhoods that have higher densities and a mix of land uses. Design elements that can improve older pedestrian safety and allow individuals to walk to a variety of locations include adequate street lighting, continuous sidewalks, raised crosswalks and other improvements that reduce the speed of vehicle traffic (Heath 2006; Lynott et al. 2009). Research suggests that mixed-use and walkable neighbourhoods help individuals maintain or increase their activity space (Beard et al. 2009). Furthermore, there is evidence that adults who live in pedestrian-oriented areas have higher levels of social capital, as measured by their social engagement, political participation, trust in other people and how well they know their neighbours (Leyden 2003).

The evidence cited above suggests that communities characterised by walkable, mixed-use neighbourhoods can increase the activity space (Schonfelder and Axhausen 2003) and social capital (Leyden 2003) of older adults, and thereby reduce social exclusion. The local ageing-friendly initiatives in the USA described below are including changes to community design as part of their efforts to promote the social inclusion of older residents:

- Age-friendly NYC (www.nyam.org/agefriendlynyc), for example, a participant in the expansion of the WHO Age-friendly Cities programme, has 
recommended a number of modifications to public spaces in New York City, including creating new pedestrian-friendly areas and implementing traffic-calming measures, as part of its efforts to make the city more ageing-friendly (Abrahms 2011; Bloomberg and Quinn 2009). In addition, as part of this initiative, the New York Academy of Medicine in 2010 began piloting two ageing-improvement districts in the city in which they will work with neighbourhood businesses to become more ageingfriendly by, for example, adding extra benches and improving street lighting (Hartocollis 2010). Similar to the efforts in Portland, Oregon described above, older adults played a key role in developing these recommendations and pilot programmes (Bloomberg and Quinn 2009). Moreover, the city council and the Mayor's office are collaborators in this effort (Bloomberg and Quinn 2009), which could increase the likelihood that recommendations will actually be implemented. However, since the pilot programmes are currently being evaluated (Hartocollis 2010) and the zoning recommendations have yet to be implemented, it is not yet possible to determine whether these changes actually will result in greater social inclusion of older adults.

- Age-friendly Philadelphia, developed by the Philadelphia Corporation for Ageing (PCA; www.pcacares.org), is another example of an initiative that includes zoning and community design as part of its efforts to promote the social inclusion of older adults. To increase the walkability of neighbourhoods and create opportunities for older adults to engage with other community members, PCA is formulating an Age-friendly Parks Checklist to encourage the incorporation of park design elements (e.g. park benches, wide pathways) that will make neighbourhood parks accessible to individuals of all ages and abilities (PCA 2011 ). Working with other public and non-profit partners, PCA has also played a role in developing a new proposed city-wide zoning code that calls for increased mixed-use zoning to foster neighbourhood social connections (Abrahms 2011 ). PCA's approach is particularly promising, as it combines expert recommendations, input from older adults, and empirical research as integral components of the initiative (PCA 2011).

\section{Transportation/mobility}

In addition to the importance of walkable neighbourhoods, improved access to other modes of transportation, including driving, public transportation and supplemental senior transportation, may also facilitate the social inclusion of older persons. While approximately 86 per cent of older adults in the USA drive, the ability to maintain a driver's licence and safely operate a vehicle declines with age, particularly after the age of $8_{5}$ (Ritter, Straight and 


\section{Andrew E. Scharlach and Amanda J. Lehning}

Evans 2002). US elders, however, report that driving is the preferred mode of transportation because it provides a sense of autonomy, identity, and independence (Glasgow and Blakely 200o). Furthermore, driving offers flexibility and convenience, particularly for older adults living in suburban communities with limited public transportation (Glasgow and Blakely 2000); and those who give up driving experience reduced social integration (Mezuk and Rebok 2008) and decreased access to community activities (US Government Accountability Office 2004).

When older adults in the USA no longer have access to their own automobiles, they typically depend on friends and family, rather than public transportation, to meet their mobility needs (Ritter, Straight and Evans 2002). Riding with others is viewed as more convenient than other transportation services (Burkhardt, McGavock and Nelson 2002); however, it also can elicit feelings of dependency (Ritter, Straight and Evans 2002). Public transportation is not a viable option for many elders, especially those who live in non-metropolitan areas (Glasgow and Blakely 2000). Approximately one-third of older adults in the USA do not have public transportation in their community (Rosenbloom and Herbel 2009). There are a range of other barriers to public transportation, such as cost, the proximity and conditions of bus and train stations, and the challenges of negotiating the overall transportation process (Cass, Shove and Urry 2005). Alternative forms of transportation, such as senior vans, often receive inadequate funding, resulting in restrictions in hours of operations, service areas (Freund 2004) and destinations (US Government Accountability Office 2004).

According to Church, Frost and Sullivan (2000), research on social inclusion rarely explores the role of transportation. For example, there is little empirical evidence of the potential benefits of suggested road design improvements to increase older driver safety, such as more visible street signs and simplified intersections (Rudinger, Donaghy and Poppelreuter 2004). Kerschner and Aizenberg (2001) recommend that public and alternative transportation services need to improve five criteria-availability, accessibility, acceptability, affordability and adaptability - if the mobility of seniors is to be improved. The impact of many of these criteria has yet to be evaluated, although there is some evidence that accessibility features can increase ridership, as the introduction of low-floor buses in Britain led to a 10 per cent increase in the number of people using public transit (Suen and Sen 2004).

Transportation and mobility are key components of a number of initiatives in the USA that are working to facilitate the social inclusion of older adults. As with the initiatives targeting community design, a strength of these efforts is the solicitation of input from community members. Also similar to the case 
examples described previously, these are new initiatives that have yet to be evaluated fully.

- Blueprint for Ageing in Washtenaw County, Michigan, an initiative that received support through the Robert Wood Johnson Foundation's Community Partnerships for Older Adults (www.partnershipsforolderadults.org), is one example of an initiative that is attempting to improve the transportation aspect of the physical environment. In surveys and focus groups across the diverse communities of Washtenaw County, older residents indicated that transportation/mobility was one of their top concerns (Blueprint for Ageing 2008). In response, Blueprint for Ageing piloted three phases of a transportation voucher programme that allowed older adults to reimburse providers, including public transit, taxis and informal care providers, for trips to any destination. Findings from an initial survey showed that the voucher programme improved elders' use of activity space and access to goods and services, particularly for low-income older adults (Blueprint for Ageing 2008, 2010). However, this was a small pilot programme (including less than 1 oo older adults in each phase) and it is unclear whether the programme can be expanded county-wide due to limited funding (Blueprint for Ageing 2010).

- The Portland Age-friendly Cities Project, described earlier, is also addressing social exclusion by working to improve the city's public transportation system for older adults and individuals with disabilities, according to the five criteria proposed by Kerschner and Aizenberg (2001).

\section{Housing}

According to a recent survey in the USA, 93 per cent of older adults in the USA would like to remain in their own homes for as long as possible (Feldman et al. 2004). This desire to age in place may stem from a strong sense of meaning older adults imbue into their homes, as well as the feelings of control and self-identity elders derive from attachment to their place of residence (Golant 2003). Older adults develop feelings of place attachment not only to their home, but to the surrounding neighbourhood as well (Phillipson 2007). Ageing in place may therefore increase the social inclusion of older adults by helping them maintain their access to neighbours and neighbouring (Forrest and Kearns 2001).

The absence of accessibility features in many homes can prevent older adults from ageing in place. It has been estimated that more than go per cent of homes and apartments in the USA are not accessible to individuals with disabilities (Steinfeld, Levine and Shea 1998). Inaccessible housing lacks 
such design features as non-slip flooring, wide entryways for wheelchair passage, grab bars in the bathroom (Pynoos, Caraviello and Cicero 2009), and a full bathroom and bedroom on the main level (AARP Public Policy Institute 2005). Federal laws in the USA mandate the inclusion of such features only in new multi-family housing (Kochera 2002). Furthermore, zoning regulations in the USA often reduce the housing options of older adults who wish to remain in their own neighbourhoods but are unable to maintain a large, single-family home. For example, they restrict land use to one single-family home per lot, and reduce the development of an accessory dwelling unit (ADU) to be used for an older family member or carer (Pynoos et al. 2008).

There are few studies that examine the impact of these housing innovations on the physical and social wellbeing of older adults. It is unclear, for example, if allowing accessory dwelling units can help older adults age in place or reduce their social isolation. Despite methodological limitations, some studies suggest that modifying the home environment is associated with improved health and social outcomes (e.g. Gitlin et al. 2001; Liu and Lapane, 20o9; Wahl et al. 2009).

The Atlanta Regional Commission's Lifelong Communities Initiative, also developed through the Robert Wood Johnson Foundation's Community Partnerships for Older Adults (www.partnershipsforolderadults.org), offers an example of a local ageing-friendly community initiative that includes housing as part of its efforts to promote elders' social inclusion (Atlanta Regional Commission 2009). The Atlanta region is dominated by lowdensity neighbourhoods with single-family homes, which potentially serves as a barrier to ageing in place. One of the major goals of this initiative is to ensure that both new and existing housing is accessible, affordable, and close to goods and services (Atlanta Regional Commission 2009). To meet that goal, Lifelong Communities brought together experts from a broad range of areas with local community residents. Participants strategised ways to provide a continuum of housing, including apartments, ADUs and supportive housing, to meet the needs of residents of all ages. While the empirical literature has yet to document the impact of a wide range of housing options on the social inclusion of older adults, housing experts (e.g. Pynoos et al. 2008) believe that offering alternatives to single-family homes will allow older adults to remain in their communities and out of an institution. However, even if the recommendations that emerged from the example above are put in place, transforming suburban neighbourhoods is a long process. Moreover, increasing densities and combining residential and commercial zones in suburban areas may be delayed or prevented by public resistance fostered by NIMBY (not in my backyard) feelings (Lehning 2012). 


\section{Summary: how communities can become more ageing-friendly and socially inclusive}

Ageing-friendly communities are characterised by physical and social environments that provide supports which enable individuals to age in place, while having opportunities to meet age-related needs through full participation in community life. Ageing-friendly communities may promote social inclusion by helping overcome physical and social barriers that deny many older adults the ability to participate fully in societal structures and access valued societal resources, whether as a result of economic disadvantage, personal limitations, disabling environments, or ageist societal norms and values. There is evidence, albeit limited, that social inclusion can be promoted through formal and informal social structures that offer meaningful social roles for older adults, promote reciprocal social exchanges that foster interdependence rather than inequity and disempowerment, and provide access to resources that promote personal wellbeing and fulfilment. The existing empirical literature also suggests that social inclusion may be promoted through physical infrastructure improvements such as walkable neighbourhoods, mobility options, and adequate housing for persons with diverse needs and abilities. As noted previously, there is some existing evidence to suggest that ageing-friendly physical and social community characteristics such as these are associated with salutary personal and communal outcomes, including better physical and mental health, greater life satisfaction and reduced risk of nursing home placement.

In recent years, a number of cities and towns throughout the USA have adopted initiatives designed to help those communities become more ageing-friendly. As we have noted, some of these initiatives include components that may contribute to the social inclusion of older community members by enhancing social integration, social support or resource access directly, or by removing physical barriers to social participation. However, these initiatives, while promising, generally reflect isolated efforts by individual communities, developed independently from one another without state or federal involvement. This lack of public involvement and co-ordination in part reflects the USA's residual approach to social welfare, relatively weak norms of equity and inclusiveness, and high levels of social, economic and cultural diversity. Moreover, because these initiatives typically are administered by non-governmental entities and financed by private foundations and other non-governmental sources, they have little recognition by, or impact on, public policy. It is notable, for example, that the USA only has two participants in the WHO's Global Age-friendly Cities programme, that those local efforts were initiated by non-governmental 
entities (Portland State University and the New York Academy of Medicine), that lack of government involvement has posed one of the greatest obstacles to implementation of programme recommendations, and that the results of these cities' efforts apparently have not spread to other US cities and states. Reliance on private funding and lack of public policy support for initiatives such as these also prompts concerns regarding their ability to be sustained once funding ends.

Concerns also have been raised regarding the comprehensiveness and inclusiveness of many of these initiatives. Some current ageingfriendly initiatives, for example, primarily include White non-Hispanic individuals who are relatively socially and economically advantaged, raising questions about their ability to meet the needs of elders of colour and those with fewer human and economic resources. Indeed, given the limited amount of government support, a substantial amount of pre-existing social, political and economic capital may well be a prerequisite for developing ageing-friendly initiatives in the USA. In this way, it seems possible that some of these initiatives might have a secondary effect of exacerbating existing disparities based on inequitable distributions of power and resources. In addition, as noted above, even the most salutary efforts at ageing-friendliness and social inclusion may have limited impact for populations suffering from social exclusion based on structural disadvantage.

\section{Research implications}

Ageing-friendliness is a relatively new, emerging concept, with substantial questions regarding the comprehensiveness, effectiveness and sustainability of initiatives such as the ones described in this article. There has been limited research to date regarding the actual effects of specific physical and social interventions, the process by which effects are achieved, or the potential role of social inclusion in facilitating that process. Rigorous evaluation is needed regarding the ability of initiatives to alter levels of social integration, social support and resource access among programme participants as well as across the broader community.

Needed are research methodologies that enable individuals to be examined holistically in the context of their physical and social environments, as those individuals and contexts change over time. Cross-national and cross-cultural research efforts are needed to examine the potential influences of sociocultural and political-economic contexts, barriers to social inclusion, meanings attributed to social inclusion and exclusion of older individuals, and the generalisability of local initiatives. 


\section{Policy implications}

Public policy has an important role to play not only in removing physical barriers to social inclusion due solely to age and ability, but also in reducing overt and covert social barriers that prevent full participation in all aspects of communal life. In the USA, some federal, state and local policies that address social inclusion have already been implemented. At the federal level, the Americans with Disabilities Act (ADA) has increased community access for persons with disabilities by, for example, requiring that public facilities remove access barriers and mandating complementary paratransit services for those unable to use public transportation. And, the Age Discrimination in Employment Act of 1967 (ADEA) has helped to protect individuals 40 years of age or older from employment discrimination. However, these policies have been predicated in large part on enhancing access to the labour force and other societal and economic structures, especially for younger adults with physical disabilities, rather than enhancing social solidarity and wellbeing for older persons.

Additional US public policy initiatives are needed to enhance the ability of older adults to age in place and participate more fully in their communities. First, local, state and federal policy makers should implement policies and programmes that could create physical environments that offer the promise of promoting social integration, social support and access to resources for older adults. Before approving a new housing development, for example, local zoning boards should assess how the mix (or lack thereof) of housing types and the incorporation (or lack thereof) of accessibility features will affect the ability of residents to age in place. States and localities should remove restrictions on accessory dwelling units to preserve affordable housing for older adults who want to remain in familiar neighbourhoods where they have developed social support networks. Mixed-use community planning should be encouraged, in order to improve the ability of older residents to move easily between their homes and the physical locations where meaningful social interaction and engagement can occur. Planning departments should prioritise sidewalk connectivity and maintenance to create more walkable neighbourhoods throughout the community. Finally, the needs of older drivers should be taken into consideration.

Many of these recommendations overlap with those put forth by the WHO Global Age-friendly Cities programme, which were identified through focus groups with older adults in 33 cities around the world (WHO 2007). The physical barriers that these policies aim to address are therefore not unique to the USA. For example, more and more individuals living in European and Asian countries are relying on automobiles for transportation (Forsyth and 
Southworth 2008), and if this trend continues older adults living in those regions may experience the potential for social exclusion that confront older ex-drivers in the USA. Indeed, researchers in Finland have documented that driving cessation is associated with decreased psychological wellbeing among older adults (Siren, Hakamies-Blomqvist and Lindeman 2004). As an example in housing, while countries such as New Zealand, Australia, Japan and those throughout Europe have adopted regulatory requirements to improve accessibility, these tend to focus on public buildings rather than residential structures and generally are poorly enforced (Scotts, SavilleSmith and James 2007). This implies that many older adults throughout the world may live in inaccessible dwellings. In a study of five European countries, Oswald et al. (2007) found that older adults whose residences lack accessibility features are more likely to have limitations in performing daily activities and experience depressive symptoms.

Beyond the removal of physical barriers, social policies and programmes can assertively facilitate access and social inclusion. Governmental and nongovernmental support is needed for community-based senior engagement initiatives that help members to age in place by reducing social isolation and unmet needs through a combination of social integration, social support and service access. Support also is needed for intentional intergenerational programmes and social structures that promote meaningful roles for older adults and provide opportunities for frequent substantive interactions among persons of all ages, promoting development of significant bridging social capital across age cohorts. In contrast to the residual, silo-based approach embodied in most US public policy, ageing-friendly community initiatives such as these call for a prevention-oriented approach, which engages diverse age groups and community stakeholders in efforts to promote the physical and social wellbeing of older individuals while enhancing community capacity for meeting the current and future needs of all community members. In under-resourced communities, such community-building efforts may need to be accompanied by an influx of external resources, rather than being seen as an alternative to governmentsponsored programmes and public expenditures (Theiss-Morse and Hibbing 2005).

Finally, public policy can help to change public attitudes about ageing and the aged by recognising and promoting the unique contributions that older community members can make to the wellbeing of the community as a whole. Rather than being seen primarily as a problem to be accommodated, it may be more beneficial to see elders as a largely untapped community resource, whose value transcends simple utilitarian functions (Roszak 1998). Overcoming physical and social barriers to social inclusion may benefit not only older adults, but entire communities. While the evidence is as yet 
limited, it seems likely that efforts to make communities more ageingfriendly may have numerous benefits for everyone.

\section{References}

AARP 200o. Fixing to Stay: A National Survey of Housing and Home Modification Issues. Available online at http://www.aarp.org/research/surveys/stats/surveys/public/ articles/aresearch-import-783.html [Accessed 1 February 2010].

AARP Public Policy Institute 2005. Livable Communities: An Evaluation Guide. AARP Public Policy Institute, Washington DC. Available online at http://assets.aarp.org/ rgcenter/il/d18311_communities.pdf [Accessed 8 July 2009].

AARP Public Policy Institute 2008. The Role of the Older Americans Act in Providing Longterm Care. Fact Sheet. AARP Public Policy Institute, Washington DC. Available online at http://assets.aarp.org/rgcenter/il/fs12r_oaa_ltc.pdf [Accessed 27 May 2009].

Abrahms, S. 2011 . Towns and cities prepare for ageing populations. AARP Bulletin. Available online at http://www.aarp.org/home-garden/housing/info-o3-2011/ towns-cities-prepare-for-ageing-populations.html [Accessed 11 May 2011 ] .

Atlanta Regional Commission 2009. Lifelong Communities: A Regional Guide to Growth and Longevity. Available online at http://documents.atlantaregional.com/llc/ LLC_Final_Report_o6_23.pdf [Accessed 11 May 2011].

Beard, J. R., Blaney, S., Cerda, M., Frye, V., Lovasi, G. S., Ompad, D., Rundle, A. and Vlahov, D. 2009. Neighborhood characteristics and disability in older adults. Journals of Gerontology: Social Sciences, $\mathbf{6 4}$ B, 2, 252-7.

Berkman, L. 200o. Social support, social networks, social cohesion, and health. Social Work in Health Care, 31, 2, 3-14.

Blair, T.R. 2010. Community ambassadors: a community-driven approach to resource access for elders. Unpublished master's thesis, University of California, Berkeley, California.

Bloomberg, M. R. and Quinn, C. C. 2009. Age-friendly NYC: Enhancing Our City's Livability for Older New Yorkers. Available online at http://www.nyc.gov/html/dfta/ downloads/pdf/agefriendlynyc.pdf [Accessed 13 December 2010].

Blueprint for Ageing 2008. Transportation Voucher Pilot Project Report. Available online at http://www.blueprintforageing.org/documents/TransportationPilot FinalReportApril_ooo.pdf [Accessed 11 May 2011].

Blueprint for Ageing 2010. Transportation Voucher Pilot Project: Phase II and III. Available online at http://www.blueprintforageing.org/documents/Trans PhaseIIandIII-FinalReport.pdf [Accessed 9 August 2011 ].

Bourdieu, P. 1986. The forms of social capital. In Richardson, J. G. (ed.), Handbook of Theory and Research for the Sociology of Education. Greenwood, New York, $24^{1-} 5^{8}$.

Burchardt, T., Le Grand, J. and Piachaud, D. 1999. Social exclusion in Britain 1991-1995. Social Policy and Administration, 33, 3, 227-44.

Burkhardt, J. E., McGavock, A. T. and Nelson, C. A. 2002. TCRP Report 82: Improving Public Transit Options for Older Persons. Transportation Research Board, Washington DC.

Cannuscio, C., Block, J. and Kawachi, I. 2003. Social capital and successful ageing: the role of senior housing. Annals of Internal Medicine, 139, 5, 395-40o.

Carstensen, L. L. 1995. Evidence for a life-span theory of socioemotional selectivity. Current Directions in Psychological Science, 4, 5, $15^{1-6 .}$ 


\section{Andrew E. Scharlach and Amanda J. Lehning}

Casas, I. 2007. Social exclusion and the disabled: an accessibility approach. The Professional Geographer, 59, 4, 463-77.

Cass, N., Shove, E. and Urry, J. 2005. Social exclusion, mobility and access. The Sociological Review, 53, 3, 539-55.

Center for Community Economic Development 20o9. Elders Who Can't Make Ends Meet in California as Measured by the California Elder Economic Security Standard ${ }^{\mathrm{TM}}$ Index. Available online at http://www.insightcced.org/uploads/cfess/New\% 2oElder\% 20Fact $\%$ 2oSheets/State\% 2otemplates/Statewide\% 20Chart\% 20Template.pdf [Accessed 16 January 2011 ].

Church, A., Frost, M. and Sullivan, K. 2000. Transport and social exclusion in London. Transport Policy, 7, 3, 195-205.

City of Fremont 201 1. Community Ambassador Program for Seniors. Available online at http://www.capseniors.org/ [Accessed 7 May 2011 ].

Clark, P. and George, L.K. 2005. The role of the built environment in the disablement process. American Journal of Public Health, 95, 1 1, 1933-9.

Community Partnerships for Older Adults 2007. Community Partnerships for Older Adults: Learning Locally. Sharing Nationally. Available online at http://www. partnershipsforolderadults.org/index.aspx [Accessed 7 July 2009].

Conway, K. and Houtenville, A. 2003. Out with the old, in with the old: a closer look at younger versus older elderly migration. Social Science Quarterly, 84, 2, 309-28.

Eheart, B. K., Hopping, D., Power, M. B., Mitchell, E.T. and Racine, D. 2009. Generations of Hope Communities. Available online at http://generationsofhope.org/ documents/GHC_White_Paper.pdf [Accessed 18 January 2011 ].

Feldman, P. H., Oberlink, M. R., Simantov, E. and Gursen, M. D. 2004. A Tale of Two Older Americas: Community Opportunities and Challenges. Center for Home Care Policy and Research, New York. Available online at http://www.vnsny.org/advantage/ AI_NationalSurveyReport.pdf [Accessed 18 May 2004].

Frey, W. H. 2007. Mapping the Growth of Older America: Seniors and Boomers in the Early 2 Ist Century. The Brookings Institution, Washington DC.

Forrest, R. and Kearns, A. 2001. Social cohesion, social capital and the neighbourhood. Urban Studies, 38, 1 2, $2125^{-43 .}$

Forsyth, A. and Southworth, M. 2008. Cities afoot - pedestrians, walkability and urban design. Journal of Urban Design, 13, 1, 1-3.

Freund, K. 2004. Surviving without driving: Policy options for safe and sustainable senior mobility. Transportation Research Board Conference Proceedings, 27, $114^{-21}$.

Gans, H. 1972. People and Plans: Essays on Urban Problems and Solutions. Routledge, London.

Giles, L. C., Glonek, G.F. V., Luszcz, M.A. and Andrews, G. R. 2007. Do social networks affect the use of residential aged care among older Australians? $B M C$ Geriatrics, 7, 24, 24-33.

Gitlin, L. N., Corcoran, M. A., Winter, L., Boyce, A. and Hauck, W. W. 2001. A randomized controlled trial of a home environmental intervention to enhance selfefficacy and reduce upset in family caregivers of persons with dementia. The Gerontologist, 41, 1, 15-30.

Glasgow, N. and Blakely, R. M. 2ooo. Older nonmetropolitan residents' evaluations of their transportation arrangements. Journal of Applied Gerontology, 1 9, 1, 95-116.

Glass, T. A., Mendes De Leon, C. F., Bassuk, S. and Berkman, L. F. 20o6. Social engagement and depressive symptoms in late life: longitudinal findings. Journal of Ageing and Health, 18, 4, 604-28.

Glass, T. A., Mendes De Leon, C. F., Marottoli, R. A. and Berkman, L. F. 1999. Population based study of social and productive activities as predictors of survival among elderly Americans. British Medical Journal, 319, 7208, 478-83. 
Golant, S. M. 2003. Conceptualizing time and behavior in environmental gerontology: a pair of old issues deserving new thought. The Gerontologist, 43, $5,63^{8-48 .}$

Guest, A. and Wierzbicki, S. 1999. Social ties at the neighborhood level: two decades of GSS evidence. Urban Affairs Review, 35, 1, 92-111.

Hanson, D. and Emlet, C. A. 2006. Assessing a community's elder-friendliness: a case example of the AdvantAge Initiative. Family and Community Health, 29, 4, 266-78.

Hartocollis, H. 2010. A fast-paced city tries to be a gentler place to grow old. The New York Times. Available online at http://www.nytimes.com/2010/o7/19/ nyregion/1 gageing.html [Accessed 18 July 2010].

Heath, G. W. 2006. The effectiveness of urban design and land use and transport policies and practices to increase physical activity: a systematic review. Journal of Physical Activity and Health, 3, 1, 55-76.

House, J. S. 1981. Work Stress and Social Support. Addison-Wesley Publishing Company, Reading, Massachusetts.

House, J. S., Umberson, D. and Landis, K. R. 1988. Structures and processes of social support. Annual Review of Sociology, 14, 1, 293-318.

Jang, Y., Mortimer, J. A., Haley, W. E. and Borenstein Graves, A. R. 2004. The role of social engagement in life satisfaction: its significance among older individuals with disease and disability. Journal of Applied Gerontology, 23, 3, 266-78.

Jette, A. 20o9. Toward a common language of disablement. Journals of Gerontology: Medical Sciences, 64A, $11,1165^{-8 .}$

Kawachi, I., Kennedy, B. P. and Glass, R. 1999. Social capital and self-rated health: a contextual analysis. American Journal of Public Health, 89, 8, $1187-93$.

Kerschner, H. and Aizenberg, R. 2001. Supplemental Transportation Programs for Seniors. AAA Foundation for Traffic Safety, Washington DC.

Klinenberg, E. 2002. Heat Wave: A Social Autopsy of Disaster in Chicago. University of Chicago Press, Chicago.

Kochera, A. 2002. Accessibility and Visitability Features in Single-family Homes: A Review of State and Local Activity. AARP Public Policy Institute, Washington DC.

Lehning, A. J. 201 2. City governments and ageing in place: facilitators and barriers to the adoption of community design, transportation and housing innovations. The Gerontologist, $\mathbf{5 2}^{2}, 3,345^{-} 5^{6 .}$

Lehning, A., Chun, Y. and Scharlach, A. 2007. Structural barriers to developing 'ageing-friendly' communities. Public Policy and Ageing Report, 17, 3, 15 -20.

Lehning, A.J., Scharlach, A.E. and Wolf, J. P. 2012. An emerging typology of community aging initiatives. Journal of Community Practice, in press.

Levitas, R. 1996. The concept of social exclusion and the new Durkheimian hegemony. Critical Social Policy, 16, 46, $5^{-20 .}$

Levitas, R., Pantazis, C., Fahmy, E., Gordon, D., Lloyd, E. and Patsios, D. 2007. The Multi-dimensional Analysis of Social Exclusion. Townsend Centre for the International Study of Poverty, London.

Leyden, K. M. 2003. Social capital and the built environment: the importance of walkable neighborhoods. American Journal of Public Health, 93, 9, 1546-51.

Liu, S.Y. and Lapane, K. L. 2009. Residential modifications and decline in physical function among community-dwelling older adults. The Gerontologist, 49, $3,344-354$.

Lynott, J., Haase, J., Nelson, K., Taylor, A., Twaddell, H., Ulmer, J., McCann, B. and Stollof, E. R. 2009. Planning Complete Streets for an Aging America. AARP Public Policy Institute, Washington DC.

Lyyra, T. and Heikkinen, R. 2006. Perceived social support and mortality in older people. Journals of Gerontology: Psychological and Social Sciences, 61B, 3, S1 $47^{-} 5^{2}$. 


\section{Andrew E. Scharlach and Amanda J. Lehning}

Marsh, A. and Mullins, D. 1988. The social exclusion perspective and housing studies: origins, applications and limitations. Housing Studies, 13, 6, 749-759.

McMillan, D. W. and Chavis, D. M. 1986. Sense of community: a definition and theory. Journal of Community Psychology, 14, 1, 6-23.

Mezuk, B. and Rebok, G. W. 2008. Social integration and social support among older adults following driving cessation. Journals of Gerontology: Social Sciences, $\mathbf{6}_{3} \mathbf{B}, 5$, S298-303.

Miller, E. A. and Weissert, W. G. 200o. Predicting elderly people's risk for nursing home placement, hospitalization, functional impairment, and mortality: a synthesis. Medical Care Research and Review, 57, 3, 259-97.

Morrow-Howell, N., Hinterlong, J. and Sherraden, M. (eds) 2001. Productive Ageing: Concepts and Challenges. Johns Hopkins University Press, Baltimore, Maryland.

National Association of Area Agencies on Ageing $\left(\mathrm{N}_{4} \mathrm{~A}\right)$ and Partners for Livable Communities 2005. The Maturing of America: Getting Communities on Track for an Ageing Population. Available online at http://www.n4a.org/pdf/MOAFinalReport. pdf [Accessed 20 July 2007].

National Council on Ageing n.d. Economic Security: Fact Sheet. Available online at http://www.ncoa.org/assets/files/pdf/FactSheet_EconomicSecurity.pdf [Accessed 18 January 2011 ].

National Senior Citizens Law Center 2010. The Medicaid Long-term Services and Supports Provisions in the Health Care Reform Law, April. National Senior Citizens Law Center, Washington DC. Available online at http://www.nsclc.org/areas/medicaid/ health-reform-ltss/at_download/attachment [Accessed 10 August 2011 ].

Navarro, V. 2002. A critique of social capital. International Journal of Health Services, 32, $3,423-32$.

Navarro, V. 2004. Commentary: Is capital the solution or the problem? International Journal of Epidemiology, 33, 4, 672-4.

Oswald, F., Wahl, H., Schilling, O., Nygren, C., Fange, A., Sixsmith, A., Sixsmith, J., Széman, Z., Tomsone, S. and Iwarsson, S. 2007. Relationships between housing and healthy ageing in very old age. The Gerontologist, 47, 1, 96-107.

Philadelphia Corporation for Ageing (PCA) 2011. Laying the Foundation for Agefriendly Philadelphia. Available online at http://www.pcacares.org/Files/PCA_AgeFriendly_WhitePaper_print.pdf [Accessed 9 August 2011 ].

Phillipson, C. 2007. The 'elected' and the 'excluded': sociological perspectives on the experience of place and community in old age. Ageing $\mathcal{E}$ Society, 27, 3, $321-42$.

Phillipson, C., Bernard, M., Phillips, J. and Ogg, J. 1999. Older people's experiences of community life: patterns of neighboring in three urban areas. Sociological Review, 47, 4, 715-39.

Portes, A. 1998. Social capital: its origins and applications in modern sociology. Annual Review of Sociology, 24, 1-24.

Putnam, R. D. 1995. Bowling alone: America's declining social capital. Journal of Democracy, 6, 1, $65^{-78 .}$

Putnam, R. D. 2004. Commentary: 'Health by association': some comments. International Journal of Epidemiology, 33, 4, 667-71.

Pynoos, J., Caraviello, R. and Cicero, C. 2009. Lifelong housing: the anchor in ageingfriendly communities. Generations, 33, 2, 26-32.

Pynoos, J., Nishita, C., Cicero, C. and Caraviello, R. 2008. Ageing in place, housing, and the law. University of Illinois Elder Law Journal, 16, 1, 77-107.

Ritter, A. S., Straight, A. and Evans, E. 2002. Understanding Senior Transportation: Report and Analysis of a Survey of Consumers Age $50+$. AARP, Washington DC. 
Rosenbloom, S. and Herbel, S. 2009. The safety and mobility patterns of older women: do current patterns foretell the future? Public Works Management and Policy, 13, $4,33^{8-53}$.

Roszak, T. 1998. America the Wise: The Longevity Revolution and the True Wealth of Nations. Houghton Mifflin Co., Boston, Massachusetts.

Rudinger, G., Donaghy, K. and Poppelreuter, S. 2004. Societal trends, mobility behavior, and sustainable transport in Europe and North America: the European Union network STELLA. European Journal of Ageing, 1, 1, 95-101.

Saelens, B. E., Sallis, J. F., Black, J. B. and Chen, D. 2003. Neighborhood-based differences in physical activity: an environment scale evaluation. American Journal of Public Health, 93, 9, 1552-8.

Satariano, W.A. 1997. The disabilities of ageing-looking to the physical environment. American Journal of Public Health, 87, 3, 331-2.

Scharf, T., Phillipson, C., Kingston, P. and Smith, A. E. 2001. Social exclusion and older people: exploring the connections. Education and Ageing, 16, 3, 303-20.

Scharf, T., Phillipson, C. and Smith, A. E. 2005. Social exclusion of older people in deprived urban communities of England. European Journal of Ageing, $\mathbf{2}$, $2,76-87$.

Scharlach, A. E. 2009. Creating ageing-friendly communities. Generations, 33, 2, $5^{-1} 1$.

Scharlach, A. E., Graham, C. and Lehning, A.J. 2012. The 'village' model: a consumer-driven approach for aging in place. The Gerontologist, 5, 3, 418-427.

Scharlach, A. E. and Lehning, A. J. 2011 . Government's role in ageing and long-term care. In Hacker, J. and O'Leary, A. (eds), Shared Responsibility, Shared Risk: Government, Markets, and Social Policy in the Twenty-first Century. Oxford University Press, New York.

Scharlach, A. and Sanchez, E. 2011 . From interviewers to friendly visitors: bridging research and practice to meet the needs of low-income Latino seniors. Journal of Gerontological Social Work, 54, 1, 73-91.

Schilling, J. and Linton, L. S. 2005. The public health roots of zoning: in search of active living's legal genealogy. American Journal of Preventive Medicine, 28, 2, 96-104.

Schonfelder, S. and Axhausen, K. W. 2003. Activity spaces: measures of social exclusion? Transport Policy, 10, 4, 273-86.

Scotts, M., Saville-Smith, K. and James, B. 2007. International Trends in Accessible Housing for People with Disabilities. Available online at http://www.chranz.co.nz/ pdfs/working-paper-2.pdf [Accessed 10 August 2011].

Silver, H. and Miller, S. M. 2003. Social exclusion: the European approach to social disadvantage. Indicators, 2, 2, 1-17.

Siren, A., Hakamies-Blomqvist, L. and Lindeman, M. 2004. Driving cessation and health in older women. Journal of Applied Gerontology, 23, 1, 58-69.

Steinfeld, E., Levine, D. R. and Shea, S. M. 1998. Home modifications and the fair housing law. Technology and Disability, 8, 1, $15^{-35}$.

Suen, S. L. and Sen, L. 2004. Mobility options for seniors. In Transportation in an Ageing Society: A Decade of Experience, Proceedings 27. Transportation Research Board, Washington DC, 97-113.

Szreter, S. and Woolcock, M. 2004. Health by association? Social capital, social theory, and the political economy of public health. International Journal of Epidemiology, 33, $4,65^{\mathrm{o}-67 .}$

Theiss-Morse, E. and Hibbing, J. 2005. Citizenship and civic engagement. Annual Review of Political Science, 8, 1, 227-49.

Therborn, G. 1995. European Modernity and Beyond: The Trajectory of European Societies. Sage, London. 


\section{${ }_{136}$ Andrew E. Scharlach and Amanda J. Lehning}

Thomas, W.H. and Blanchard, J. M. 20og. Moving beyond place: ageing in community. Generations, 33, 2, $12-7$.

Townsend, P. 1979. Poverty in the United Kingdom. Penguin, London.

US Department of Health and Human Services 2010. A Profile of Older Americans: 20Io. Available online at http://www.aoa.gov/aoaroot/ageing_statistics/Profile/ 2010/docs/2010profile.pdf [Accessed 10 May 2011].

US Government Accountability Office 2004. Transportation-Disadvantaged Seniors: Efforts to Enhance Senior Mobility Could Benefit from Additional Guidance and Information. US Government Accountability Office, Washington DC.

Wahl, H., Fange, A., Oswald, F., Gitlin, L. N. and Iwarsson, S. 2009. The home environment and disability-related outcomes in ageing individuals: what is the empirical evidence? The Gerontologist, 49, 3, 355-67.

Warburton, $\mathrm{Ng}$ and Shardlow 201 2. Ageing $\mathcal{E}^{2}$ Society, oo, o, oo-oo (the editorial for the special issue).

World Health Organization (WHO) 2007. Global Age-friendly Cities: A Guide. Available online at http://www.who.int/ageing/publications/Global_age_friendly_cities_ Guide_English.pdf [Accessed 10 August 2011 ] .

Accepted 25 April 2012

Address for correspondence:

Andrew E. Scharlach Ph.D.

School of Social Welfare, University of California, Berkeley, 120 Haviland, mc7400, Berkeley, CA 94720-7400, USA.

E-mail: scharlach@berkeley.edu 